\title{
International English and ergonomics: a romance in the making?
}

\author{
Roddy Kay ${ }^{1}$ \\ Examinations Manager, Cambridge ESOL Centre BR119, clo Cultura Inglesa, Av Visconde de Albuquerque, 205, \\ Madalena, 50.610-090 Recife-PE, Brazil
}

\begin{abstract}
This paper argues that it would be useful for ergonomists and experienced English Language Teaching (ELT) professionals to collaborate as this would be of substantial interest to both sets of professionals. The ongoing debate in ELT on International English (IE) might usefully help to guide ergonomists if and when they require to judge that English is used at appropriately high levels in the workplace in non-English speaking countries. It may also help ergonomists who are non-native speakers (NNSs) of English to gain greater access to the top specialist journals and to found new e-journals on Ergonomics in English that deserve international recognition. At the same time ELT specialists would have great interest in advising ergonomists on these matters, in part, as a means of testing current hypotheses on the tendencies for new varieties of English to develop and win acceptance both from native and non-native speakers of English as setting standards of communicative competence in English both for end users of English in their professional lives and for well-structured and clear written academic debate.
\end{abstract}

Keywords: International English, Ergonomics, Common European Framework of Reference for Languages, print and electronic journals

\footnotetext{
${ }^{1}$ Corresponding author: Roddy Kay. E-mail: roddy@nlink.com.br Tel: +55 81 3241-4567
} 


\section{Introduction}

The debate on International English (IE), might usefully guide ergonomists if and when they require to judge that English is used at appropriately high levels in the workplace in non-English speaking countries. It may also help ergonomists who are nonnative speakers (NNSs) of English to gain greater access to the top specialist journals and to found new e-journals on Ergonomics written in English that deserve international recognition and attract contributions from leading figures in Ergonomics including native speakers of English.

This debate in the fields of English Language Teaching (ELT) and Applied Linguistics is taking place within the context of the globalization of the economy and, indeed, of higher education. Globalization requires industry, commerce and academics to be polyglot. For better or worse, in sickness or in health, one of these languages will be English.

This paper therefore sets out to show where and how new varieties of English have been developing; what support leading ELT professionals and Applied Linguists are giving to these varieties and to argue that it may be possible for ergonomists in partnership with experienced ELT professionals to make use of the new standards that are being set for English. First, this may assist ergonomists when, on appropriate occasions, they have to reach some judgment on whether the level of English attained and/ or used by their clients meets international regulatory standards. Secondly, this trend towards different varieties of English may be having an impact on the standards set by renowned specialist journalists and similarly may help set new and yet appropriate linguistic standards for ergonomists who wish to found electronic journals written in English that will attract international attention and contributors.

To show this, Section 2 of this paper gives an outline account of the reasons why several varieties of English have developed and what issues have arisen from this that have led some to postulate that one or more new varieties of English called International English (IE) are already in use. In Section 3, the author reports on his experience as a reviewer of the linguistic aspects of academic papers and on his views on why some academic articles are rejected, ostensibly on linguistic grounds alone. Section 4 sets out issues of core interest to ergonomists that arise from the previous sections and the conclusion invites ergonomists to seek partnerships with ELT specialists with a view to tackling the issues raised. It is likely that once such partnerships are begun that ergonomists will raise complementary matters with ELT specialists.

\section{Why and how other varieties of English have developed}

A review of the English Language Teaching (ELT) literature shows the use of English as a global language moved from native speaker varieties being transplanted from the mother country to that of developing into varieties that gained official status especially in Higher Education and public administration in countries such as India, Nigeria, and the Philippines.

From the 1970s on, large numbers of foreigners who spoke English as L1 or as a second language (L2) went to work in other countries, typically, oilrich nations. Simultaneously, greater union in Europe saw English become an L2 used daily by educated professionals [1]. Indeed, English had become the medium of instruction of around 2,400 higher education programmes in Europe excluding the United Kingdom by 2007 [2, 3].

\subsection{Issues arising from new varieties of English gaining local and regional acceptance}

Although there may be some Indians who still do not fully accept Indian English as a standard that has parity of esteem with British English, the fact is that most educated speakers of English on the subcontinent do. This is also reflected in other countries, normally those that were once colonies of the British Empire, where English, while not the first language, has official status. Similarly, it is argued that the large movements of people to other countries where English does not or did not have an official status but nevertheless became the main medium of communication has led to greater toleration being shown to deviations from native speaker English rules and conventions especially in oral communication.

Secondly, not long after China decided to adopt English as L2 [4], 3 out of 4 competent users of English in the world were deemed to be NNSs of English [5, 6]. While the nature and level of this competence can and should be challenged [7], it is nevertheless a fact that, at the very least, in everyday routine transactions, successful communication in English is made by non-native speakers of English 
who vastly outnumber native speakers of English and who most often use English to communicate with those whose L1 is not English. In other words, it is undeniable that English is being successfully used by at least around five hundred million people to communicate both with native speakers of English but more frequently with speakers of other languages. Moreover, among the more educated this is leading to changes in written English that are becoming generally acceptable. This form of English is known variously as Global English, English as a Lingua Franca or, as in this paper, International English (IE).

\subsection{How some Applied Linguists and ELT Professionals have viewed and responded to the emergence of IE}

To ensure the teaching and use of English does not become a medium of linguistic imperialism $[8,9]$ and to reflect the reality of NNSs being in the large majority, serious long-term academic study is currently trying to determine to what extent IE is evolving and can be described. The Vienna-Oxford International Corpus of English (VOICE) and the work of Professor Jennifer Jenkins are prime examples of this $[10,11,12,13,14,15]$.

Secondly, best practice in language teaching and testing in terms of setting equal and appropriate levels of achievement in learning an L2 is close to achieving global acceptance. The vehicle for this is the Common European Framework of Reference for Languages; Learning Teaching Assessment (CFER) [16]. However, it is currently being emphasised by its prime movers that CEFR should be seen, as its name indicates, as a framework and not a strait-jacket i.e. it offers suggestions that need to be adapted to local practices and realities.

\section{The author's experience as a reviewer of the linguistic aspects of academic articles}

The author reviews texts in English by Brazilian academics including Ergonomists. Therefore, he is familiar with the problems in English that some of them have. Academic reviewers sometimes ask him to reconsider his linguistic review. This can include criticism of the mode of discourse rather than because of error or lack of clarity.

The uncharitable thought occasionally arises that such criticism is undeservedly harsh and may be a smokescreen behind which academic reviewers conceal their inability to articulate their contestation of the content or their unwillingness to do so, for whatever non-linguistic reasons. Yet, any deviations from native speaker norms of writing are legitimately subject to such criticism. Perhaps, as norms of International English gain acceptance, such forms of adverse criticism can be challenged more successfully than at present by appeals to editors, based on evidence of changes to English where these can be shown to be gaining world-wide currency.

\section{Core issues for ergonomists arising from the emergence of International English}

\subsection{A summary of the context}

Codifying IE is well underway as exemplified in the publications of VOICE and Jenkins. This is likely to result in several new varieties of English influenced by L1 features of given language groups becoming acceptable in academic discourse, perhaps at first in countries where English is not the L1 of the majority. A point of interest here is the standard set for written English on international campuses i.e. where a university from a country where English is L1 has set up a campus in another country or on distance learning courses that potentially include nonnative speakers of English participating online from their home country. It is likely that, in these situations, there is greater toleration, however small, of deviation from the written standards expected when study is presential at the institution in its home country. The author is not aware of any studies on this to date.

Secondly, at a very pragmatic level, the author, as a result of reviewing manuals, instructions etc. from manufacturers, commerce and the service industries, is aware the quality of English of such texts is often poor and sometimes unintelligible - something which ergonomists must be aware of but may not be confident about commenting on.

Thirdly, academics who are NNSs of English are often frustrated by their inability to nuance what they wish to say in English and by being obliged to use a mode of discourse that is different from their L1. They see these as forming invisible barriers to making their work better known in renowned journals. One response has been a proliferation of ejournals published in English. For example, Costa [17] reports that there were "more than 800 scholarly electronic journals created under OJS, and more than 
30 university institutional repositories well implemented" in Brazil by 2010.

\subsection{Specific English language issues of interest to ergonomists}

Given the impact that IE already has or is likely to have including on the everyday practices of ergonomists' clients and on the academic discipline of Ergonomics whether at the level of teaching or research, ergonomists may well wish to reflect on the following issues:

- When international regulations require excellent English from post-holders e.g. air traffic controllers, should ergonomists check this is so? How can ergonomists measure this and how should shortcomings identified be reported on and followed up?

- If manuals and instructions written in languages other than that of the country of export are inadequate or ambiguous, is it the ergonomist's responsibility to identify these and recommend that the manufacturer or service provider take corrective actions? This is especially important when inadequate instructions etc. could lead to injuries or deaths. What tools can help ergonomists make judgments about this?

- Should ergonomist's Associations persuade editors of top journals to adjust the standard of English required to one that conforms to the findings of the leading Applied Linguists and ELT authorities on IE? and

- Similarly, what editorial standards for English should e-journals insist on? How can it be ensured a non-NS standard does not detract from high quality content and that distinguished ergonomists whether or not NSs of English value such e-journals? Who in Ergonomics should advocate this point of view?

\section{Conclusion and suggestions for collaboration}

The author is aware that ergonomists place a high value on a multidisciplinary approach to their work and is confident that many highly qualified and experienced ELT professionals in whatever country would have great interest in collaborating with them in any projects that may arise from any of the observations and suggestions made. This is not to suggest that there are off-the-shelf solutions [18]. Any that do exist are likely to be limited to specific training for targeted personnel who need to enhance a limited range of language skills in a short period of time [19].

Tentative examples of the kinds of new approaches that might be considered are:

a) If there is no English examination designed for the special purposes of a high-profile, high-risk profession, is it for the ergonomist to suggest that the professional association should consider the need for one and should approach an appropriate examination body? If such an exam does exist, do the professionals who have taken it find that any language skills or specialist areas or areas of general need are inadequately covered? To whom should they express this and how does this get reviewed at an international level? For how long should a positive result in such an exam be considered valid?

b) Perhaps ELT professionals could draw up guidelines for ergonomists on the types of error that are unacceptable in manuals and instructions written in English. This of course presupposes that the ergonomist who is a NNS of English and would use such guidelines has at least an upper intermediate knowledge of English (i.e. the B2 level on the CEFR scale)

c) Is there evidence that one or more specialist journals used by ergonomists regularly publish articles that are written in different varieties of English? If so, how can such evidence be used to persuade other journals to do likewise? If not, perhaps in partnership with an ELT professional, a representative group of ergonomists could explore with selected journals if the journal would be prepared to consider doing so in the light of the global movement towards IE and/or to what extent the journal approached considers that it does allow deviation from an educated native speaker standard of written English. The results of any such survey should be published so they can be shared with ergonomists worldwide.

d) Similarly, perhaps the editorial board of a new ergonomics e-journal to be produced in English in a country where English is not L1 would wish to work with an ELT professional on drawing up guidelines for the standard of written English they expect by attempting to specify what deviations from a standard variety of English are and are not unacceptable. This will include testing these guidelines by identifying written articles that follow them and subsequently seeking the opinion of ergonomists, who are and are not NSs of English, on the impact that a text that is clear and well-argued but not fully in accordance with a NS variety of English has on them. 
Thus, the cutting edge of joint ELT/ Ergonomics activity is likely to be in helping to define or confirm standards for a variety of International English respected throughout the profession of Ergonomics. It is at this interface between Ergonomics and ELT that out of the romance of blazing new trails together our two professions may be wed!

\section{References}

[1] D. Crystal, English as a global language Cambridge: CUP (2003)

[2] J.A. Coleman, English-medium teaching in European higher education Language Teaching, 39: 1-14 Cambridge University Press (2006) doi: 10.1017/S026144480600320X Published online: 2006

[3] B. Wächter and F. Maiworm, English-Taught Programmes in European Higher Education. The Picture in 2007. ACA Papers on International Cooperation in Education. Bonn: Lemmens. (2008),

[4] Y. Hu, China's foreign language policy on primary English education: What's behind it? Language Policy Volume 6, Numbers 3-4, 359-376 (2007) doi: 10.1007/s10993-0079052-9

[5] D. Graddol, English Next British Council (Rev.ed.) 2007 Available at: http://www.britishcouncil.org/learningresearch-english-next.pdf

[6] B. Kachru, World Englishes: critical concepts in linguistics, Volume 4, Publisher: Taylor \& Francis (2006)

[7] A. Maley Global English? Implications for the teacher CamTESOL Conference on English Language Teaching: Selected Papers, Volume 5, 2009 pp. 16-22

[8] A. Pennycook, Global Englishes and transcultural flows Routledge (2007)

[9] R. Philippson, Linguistic Imperialism OUP (1992)

[10] B. Seidlhofer, The VOICE of ELF - English as a Lingua Franca. What's New? Autumn/Winter 2004, p 8-9

[11] B. Seidlhofer, Introducing English as a Lingua Franca Synergies Europe No 3 2008: 25-36

[12] B. Seidlhofer, Giving VOICE to English as a Lingua Franca In: From International to Local English and back again R. Facchinetti, D. Crystal, and B. Seidlhofer, (eds) Frankfurt: Peter Lang (2010) p 147-163

[13] J. Jenkins, The Phonology of English as an International Language: new models, new norms, new goals OUP (2000)

[14] J. Jenkins, English as a Lingua Franca: Attitude and Identity Oxford: Oxford University Press (2007)

[15] J. Jenkins, World Englishes. A resource book for students London: Routledge, 2nd ed. (2009)

[16] The Council of Europe Common European Framework of Reference for Languages: Learning, Teaching Assessment Cambridge, CUP (2001)

[17]S.M.S. Costa, Development and Practices of Open Access in Brazil Presentation at Berlin 8 Open Access Conference October, 2010 Available at: www.berlin8.org Accessed on April 24, 2010

[18] B. Björkman, 'So where we are?' Spoken lingua franca English at a technical university in Sweden English Today (2008), 24: 35-41 Cambridge University Press doi:

10.1017/S0266078408000187 Published online: 2008

[19] A. Mauranen, 'Academic English as lingua franca-a corpus approach'. TESOL Quarterly (2003) 37: 513-27 